\title{
A study on effect of bank resources and consumption on liquidity
}

\author{
Hussein Panahian, Hassan Ghodrati and Mohammad Ali Parvishi*
}

Department of Management and Accounting, Kashan Branch, Islamic Azad University, Kashan, Iran

\section{H R O N I C L E}

Article history:

Received January 4, 2014

Accepted 1 June 2014

Available online

June 92014

Keywords:

Liquidity

Liquidity management

Resources and expenses

Trend analysis

Bank Shahr

\section{A B S T R A C T}

\begin{abstract}
Liquidity management in banks is a conflict between risk and return. On the one hand, the lack of liquidity, in addition to imposing heavy costs of providing resources (including borrowings from the central bank at elevated rates), may also lead banks to face with bankruptcy. On the other hand, the maintenance of excessive liquidity than needed will destroy investment opportunities and potential profitability. Therefore, for proper liquidity management, it is necessary to understand the factors affecting this sector to be able to exert control on each of the elements, and to prevent the incidence of problems or even crisis thereby optimize the bank profitability as far as possible. This study aimed to analyze the resources, expenses, and liquidity operating as the main activity parameters in Bank Shahr. During the study timeframe (2010 until the end of 2012), every 15 days was selected as the sample community, which were selected due to a 15-day trend analysis using census method and not by random sampling. The related data concerning each of the items, i.e. resources, expenses, and liquidity were collected and analyzed by linear regression based on time or periods of time. The above items were compared through analysis of the relative contribution to the total ratio and correlation analysis. The results showed that the growing trends of resources and expenses almost coincide and followed a specific trend and, in general, the growing trend of the resources was rising with a higher slope compared with those of expenses and liquidity. In addition, the growing trend of liquidity was almost identical throughout the entire period of study and no unusual trend was observed.
\end{abstract}

(C) 2014 Growing Science Ltd. All rights reserved.

\section{Introduction}

Banks and financial and monetary institutions are the most primary economic sectors in each country. In recent years, privatization of some Iranian banks has led to a new competitive environment for private banks and, therefore, evaluation of the banks' performance has gain particular importance. Liquidity management in banks is a conflict between risk and return. On the one hand, the lack of liquidity, in addition to imposing heavy costs of providing resources (including borrowings from the central bank at elevated rates), may also lead banks to face bankruptcy. On the other hand, the maintenance of excessive liquidity may destroy investment opportunities and potential profitability. Therefore, for proper liquidity management, it is necessary to understand the factors influencing this

*Corresponding author

E-mail addresses: m.p.old.king@gmail.com (M. A. Parvishi) 
sector to be able to exert control on each of the elements and to prevent the incidence of problems or even crisis thereby optimize the bank profitability as far as possible. Banks depend on a variety of monetary and financial markets through numerous depositors and borrowers, and they are subject to different risks. Hence, banks have always tried to predict and to maintain their optimum amount of cash needed by using various tools and methods. This section will have an overview of the structure of assets and liabilities, liquidity models, and the predominating risks in the banks (Fecht et al., 2011; Calvo, 2012). This study aimed to analyze the resources, expenses, and liquidity operating as the main parameters in one of Iranian banks named Bank Shahr. During the study period from 2010 to the end of 2012, every 15 days was selected as the sample community, which were selected due to a 15-day trend analysis using census method and not by random sampling. The related data concerning each of the items, i.e. resources, expenses, and liquidity were collected and analyzed by linear regression based on time or periods of time. The above items were compared through analysis of the relative contribution to the total ratio and correlation analysis.

\section{Literature review}

Lovin (2013) investigated the effect of a liquidity shock induced by depositors' behavior on bank portfolio management during financial crises in a system without deposit insurance. The study detected that banks reacted to the liquidity shock sensitively through an increase in their cash holdings not by liquidating bank loans but by selling securities in the financial market. In addition, in their study, banks exposed to local financial contagion adjusted the liquidity of their portfolio mainly by actively selling and buying their securities in the financial market. Distinguin et al. (2013) studied the relationship between bank regulatory capital and bank liquidity measured from on-balance sheet positions for European and US publicly traded commercial banks. They reported that banks decrease their regulatory capital ratios when they encountered higher illiquidity as defined in the Basel III accords or when they created more liquidity. Imai and Takarabe (2011) investigated the causal impacts of liquidity shocks on credit supply by the endogenous relationship between loan demand and liquidity position of banks. They reported that during the period of transition from a blanket guarantee to a partial guarantee, weak banks influenced from a large outflow of partially insured time deposits. Hauck and Vollmer (2013) analyzed a government's incentives to provide financial assistance to a public bank hit by a liquidity shock. They reported that discretionary decisions about emergency liquidity assistance could result in either excessively small or excessively large liquidity injections in a wide variety of circumstances. In addition, adding a lender of last resort does not generally ensure a socially optimal policy. Balasubramanyan and VanHoose (2013) performed a a dynamic banking model survey and their results showed that imposing an LCR constraint generally had theoretically ambiguous impacts on the stability of banks' optimal dynamic balance-sheet paths.

\section{Research hypotheses}

The proposed study of this paper investigates the relationship between the resource components with the expenses and liquidity in banking industry and the study is implemented on the information of one of Iranian banks named "Bank Shahr". The study also investigates the trend on bank's resources, expenses, liquidity and the relationships between these items. The survey collects 15-day period information over the period 2010-2012. Since there are 24-point data, we end up having 72 sample study. The study uses descriptive, correlation analysis and simple regression analysis to examine the data. Fig. 1 shows different expenses/resources. For trend analysis, linear regression model was used as $\mathrm{Y}=\mathrm{f}(\mathrm{t})$, where $\mathrm{Y}$ is each of resource item, expenses, liquidity, total resources, total expenses, and $t$ is the 15-day periods every year.

\section{Research findings}

This section describes the findings and discusses the analysis of resources and expenses and they are also compared. 
Expenses (independent variables)

Increase or decrease in:

1- Receivables from central bank and
government
2- Public and private facilities and their
related receivables past due

3- Documentary credits and guarantees for debtors and their related receivables past due

4- Other expenses (other assets) including investments and partnerships, immovable property, intangible and other assets

5- Both operational and non-operational costs
Resources (independent variables) Increase or decrease in:

1- Types of deposits including loan bona
deposits, prolonged and other deposits
2- Governmental deposits including instant
and prolonged deposits from banks
3- Facilities received from central bank or
other banks
4- Other resources (other liabilities) such as
pre-pays by governmental and non-
governmental customers and facilities from
foreign exchange reserves
5- Capital resources, including shareholders'
equity and incomes (including interest and
commitment of funds received, commissions
and other incomes)

Fig. 1. Analytical model of research

Table 1

Descriptive statistics of the data (non-coefficient numbers are in Million Rials)

\begin{tabular}{|c|c|c|c|c|c|c|c|c|}
\hline Variables & Mean & Mein & Variance & $\begin{array}{l}\text { Standard } \\
\text { deviation }\end{array}$ & $\min$ & $\max$ & $\begin{array}{l}\text { Coefficient of } \\
\text { skewedness }\end{array}$ & $\begin{array}{l}\text { Elongation } \\
\text { factor }\end{array}$ \\
\hline Fund & 9799527 & 11315583 & 2.515 & 501465 & 2575669 & 17053707 & -0.121 & -1.606 \\
\hline loan bona deposits & 3004360 & 2675139 & 1.455 & 1206126 & 1556858 & 7570221 & 1.777 & 3.500 \\
\hline Prolonged deposits & 3101562 & 2104564 & 4.406 & 2098978 & 900638 & 7877057 & 0.742 & -0.905 \\
\hline Other deposits & 181324 & 31119 & 1.602 & 400240 & 8398 & 2292470 & 4.442 & 21.445 \\
\hline From banks deposits & 2169116 & 1908669 & 2.975 & 1724717 & 1472788 & 5463783 & 0.571 & -0.945 \\
\hline Debt to the Central Bank. & 405856 & 126624 & 3.077 & 554221 & 73412 & 2000267 & 1.708 & 1.961 \\
\hline Get bank loans & 1104316 & 1062237 & 1.561 & 395113 & 394521 & 2021070 & 0.403 & 0.625 \\
\hline Pre-pay by customers & 1025150 & 1007855 & 3.152 & 177538 & 682284 & 1568838 & 0.867 & 1.064 \\
\hline $\begin{array}{l}\text { Facilities from foreign exchange } \\
\text { reserves }\end{array}$ & 6096005 & 4893592 & 5.282 & 2298330 & 3196941 & 9664811 & 0.220 & -1.779 \\
\hline Incomes & 10510170 & 2673713 & 1.759 & 1326 & -440510 & 55517879 & 1.279 & 0.920 \\
\hline $\begin{array}{l}\text { Receivables from central bank and } \\
\text { government }\end{array}$ & -694446 & -21081 & 5.284 & -2298784 & 0 & 9263819 & 3.357 & 10.041 \\
\hline Installment sale facilities & -8513871 & -8358567 & 1.489 & -3858970 & -207207 & 1876572 & 0.424 & 0.446 \\
\hline Civil Partnership Facility & -2801509 & -2188564 & 2.372 & -1540073 & -802468 & 5278781 & 3.357 & -1.474 \\
\hline Other Facilities & -10581460 & -10329260 & 3.525 & -5937146 & -4578068 & 27017421 & 1.107 & 0.588 \\
\hline Their related receivables past due & -2180213 & -2026810 & 5.467 & -739406 & -838801 & 3719754 & 0.050 & 0.731 \\
\hline Debtors LC \& LG & -2048293 & -1912544 & 4.487 & -669846 & -977274 & 328226 & 0.094 & -1.193 \\
\hline Receivables past LC \& LG & -1318448 & -1424780 & 3.451 & -587492 & -145553 & 2320875 & -0.602 & -0.548 \\
\hline Other assets & -5332467 & -4254676 & 1.132 & -3364369 & -1773405 & 14442702 & 0.644 & 0.629 \\
\hline Costs & -1135857 & -2836364 & 2.190 & -14798992 & 300098 & 65212201 & 1.534 & 2.181 \\
\hline
\end{tabular}

\subsection{Description of the findings}

As mentioned earlier, each of the bank's resources and expenses were classified into nine categories. At the beginning of the first and the fifteenth of each month, cash balances were collected using bank finance management reporting software and they were classified via Excel spreadsheet. According to the descriptive statistical data, the following results were obtained using SPSS software.

- The mean and median values are close together for most variables. This feature was not optimal among the variables of debt to the central bank, receivables from the central bank and the government and other resources, loans from foreign exchange reserves, civic facilities, and other assets and expenses. This was due to the presence of large changes in the remains, and also to the unchanged remains during the past few successive months.

- With the exception of cash and maturities for letters of credit and guarantees having a skewedness to the left, the remaining variables skew to the right because their coefficients of skewedness is positive. 
- The stretching of more than a half of the variables is above and a half is shorter than the normal distribution (those whose stretch coefficient is negative).

\subsection{Analyzing the resources items}

During the 15 -day timeframe for data collection, the data were analyzed using trend analysis. In this analysis, the horizontal (independent variable) and vertical (dependent variable) axes are, respectively, the timeframe and any of the resources items. The resources employed in the bank under review include deposits, loans received from other banks and other sources. The first part deals with the trend analysis of each of these items, and the overall trend in total resources and finally, they are compared with each other.

\subsubsection{Trend analyses of the loan deposits:}

Loan deposits without interest and awards are provided to encourage the depositors. Fig. 2 shows the trends of these deposits indicating that these deposits had relatively upward trend over time;

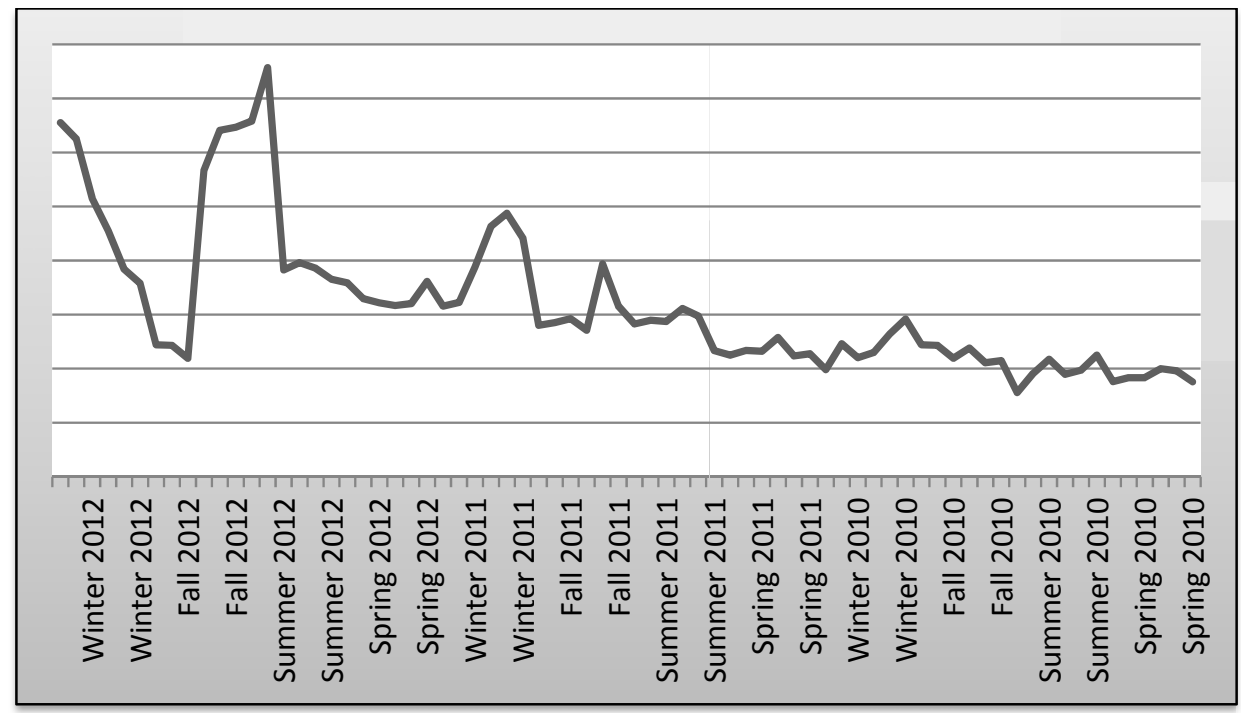

Fig. 2. Trend of loan deposit

As we can observe from the results of Fig. 2, there was a slow growth during the early period until winter 2011. With the change of the Mayor and of his attitude to Bank Shahr in October 2012, noticeable changes in the bank's loan deposits occurred but the problem was gradually solved. The general trend of changes in loan deposits was estimated using regression (Table 2). Using the estimated parameters, the regression equation is as follows: $\mathrm{Y}=\mathrm{f}(\mathrm{t})=-10000000+11585 \mathrm{t}$ and the regression has a positive slope for each timeframe showing an ascending trend. The estimated equation indicates over $48.5 \%$ of the changes.

\section{Table 2}

Estimated trend line for loan deposits

\begin{tabular}{ccc}
\hline Row & Parameter & quantity \\
\hline 1 & The width of the source & -10000000 \\
3 & The slope of the line & 11585.138 \\
\hline
\end{tabular}

\subsubsection{Trend analysis of prolonged deposits}

These deposits are associated with interest and awards and they are provided to encourage the depositors. Fig. 3 shows the trends of these deposits indicating that these deposits had relatively upward trend over time: 


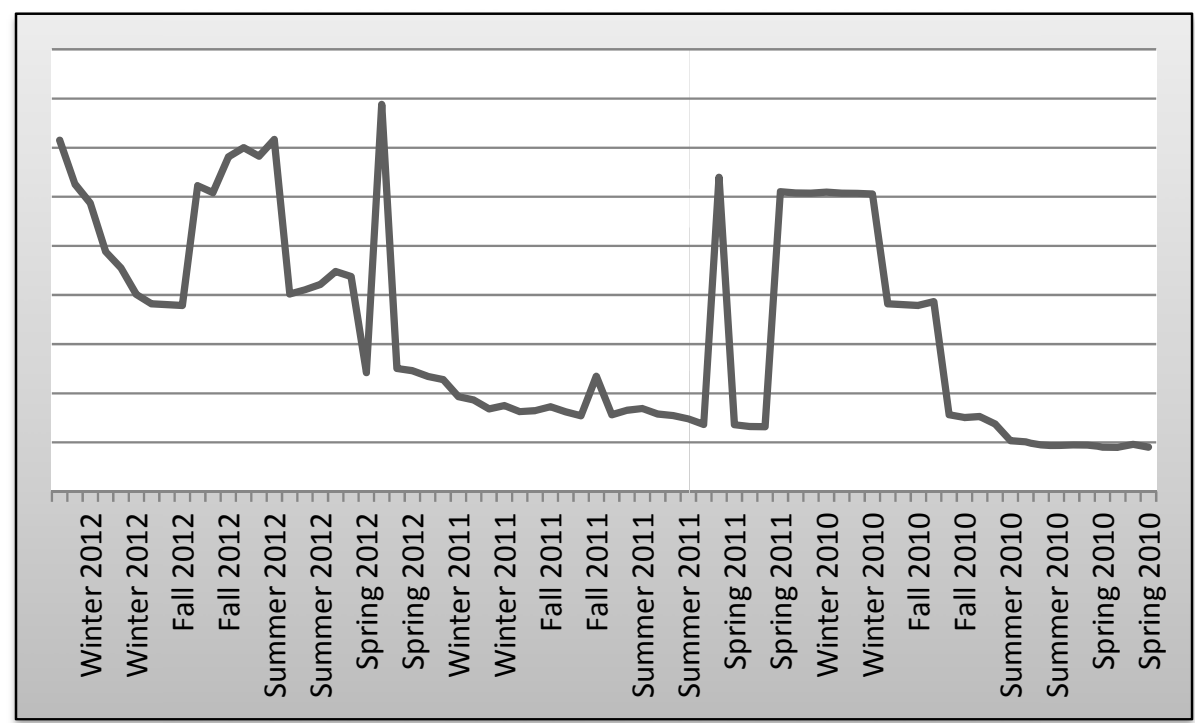

Fig. 3. Trend of prolonged deposits

The figure shows slow growth during the early period until spring 2011 . The reason is because in winter 2011, an inflation and rising interest rates of investments led to a rapid growth in these deposits. The general trend of changes in the prolonged deposits was estimated using regression presented in Table 3. Using the estimated parameters, the regression equation is as follows: $\mathrm{Y}=\mathrm{f}(\mathrm{t})=$ $-10000000+11809 t$, which has a positive slope for each timeframe showing an ascending trend. The estimated equation indicates over $19.6 \%$ of the changes.

Table 3

Estimated trend line of prolonged deposits

\begin{tabular}{ccc}
\hline Row & Parameter & quantity \\
\hline 1 & The width of the source & -10000000 \\
3 & The slope of the line & 11809.073 \\
\hline
\end{tabular}

\subsubsection{Analysis of the expenses items}

During the 15-day timeframe for data collection, the data were analyzed using trend analysis. In this analysis, the horizontal (independent variable) and vertical (dependent variable) axes are the timeframe and any of the resources items, respectively. The resources employed in the bank under review include total credits, the maturities and deferred receivables, and finally other expenses. The first part deals with the trend analysis of each of these items, and the overall trend in total resources and finally, they are compared with each other.

\subsubsection{Trend analysis of facilities for Buy Now Pay Later}

This includes the facilities given to governmental and non-governmental clients. Fig. 4 shows the trends of these deposits indicating that these deposits had relatively upward trend over time. Fig. 4 shows slow growth during the early period until October 2011 and they were associated with specific changes during the remaining period. Since October 2012, the bank facilities policy led to a rapid growth in these deposits. The general trend of changes in the facilities for Buy Now Pay Later was estimated using regression (Table 4). Using the estimated parameters, the regression equation is as follows: $Y=f(t)=-5000000+5133 t$, which has a positive slope for each timeframe showing an ascending trend. The estimated equation indicates over $33.9 \%$ of the changes. 


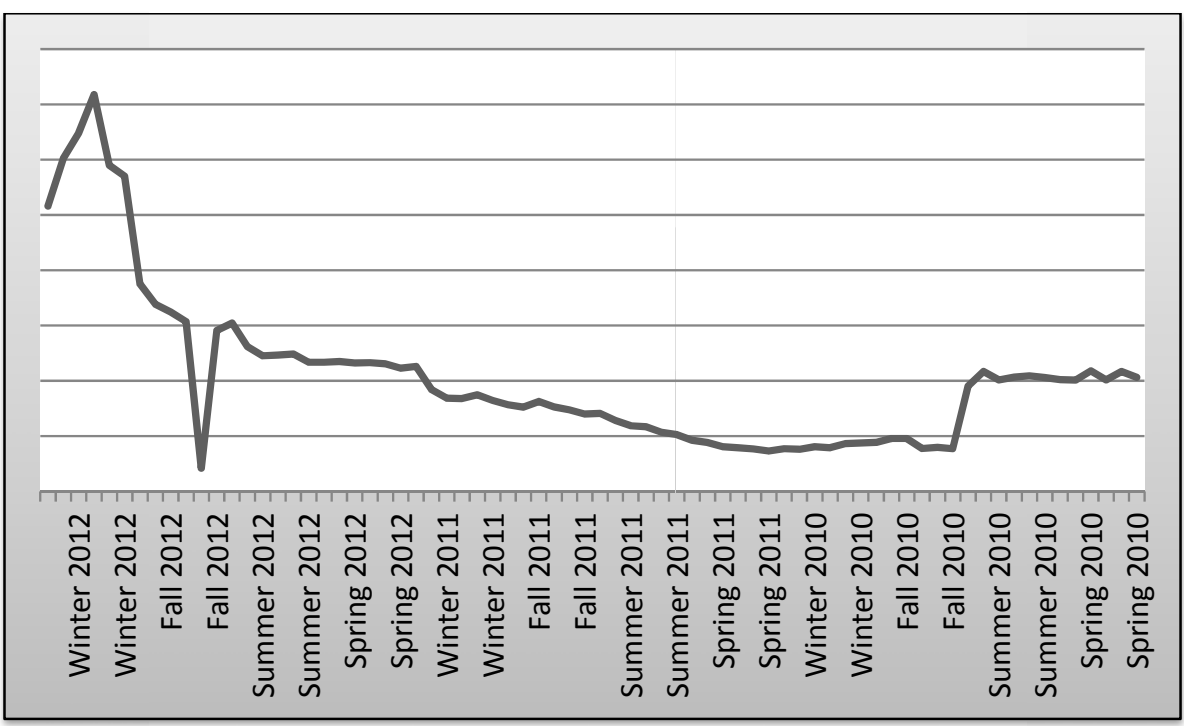

Fig. 4. Trend of facilities for Buy Now Pay Later

Table 4

Estimated trend line for prolonged deposits

\begin{tabular}{ccc}
\hline Row & Parameter & quantity \\
\hline 1 & The width of the source & -5000000 \\
2 & The slope of the line & 5133.071 \\
3 & The coefficient of determination & 0.339 \\
\hline
\end{tabular}

\subsubsection{Trend analysis of facilities for civic participation}

The heading of these facilities is remarked and non-remarked. Fig. 5 shows the trend of this outline during the studied timeframe indicating that these deposits had relatively upward trend over time

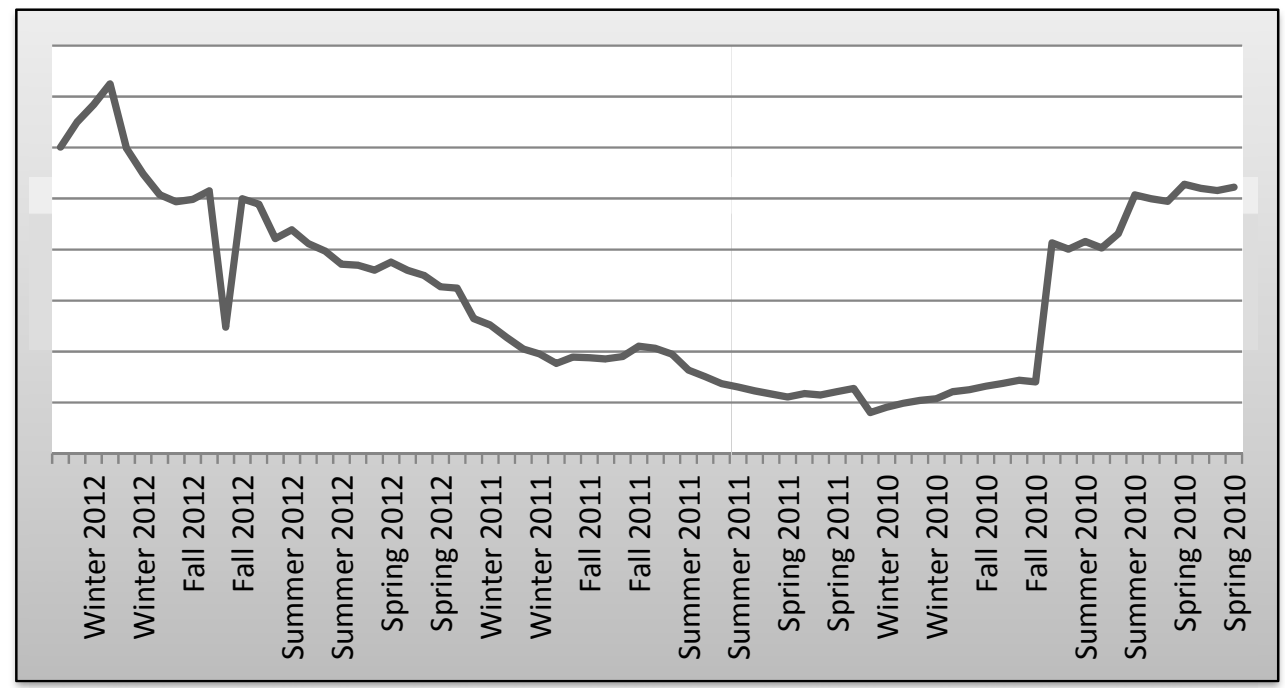

Fig. 5. Trend of facilities for civic participation

Fig. 5 shows slow growth during the early period until October 2012 and they were associated with specific changes during the remaining period. The general trend of changes in the facilities for civic participation was estimated using regression (Table 5). 
Table 5

Estimated trend line facilities for civic participation

\begin{tabular}{ccc}
\hline Row & Parameter & quantity \\
\hline 1 & The width of the source & -7000000 \\
2 & The slope of the line & 8575.656 \\
3 & The coefficient of determination & 0.149 \\
\hline
\end{tabular}

Using the estimated parameters, the regression equation is as follows: $\mathrm{Y}=\mathrm{f}(\mathrm{t})=-7000000+8576 \mathrm{t}$, which has a positive slope for each timeframe showing an ascending trend. The estimated equation indicates over $14.9 \%$ of the changes.

\subsubsection{Analyzing the trend for debtors of credits letters and guarantees}

This heading includes debtors of letters of credits letters and guarantees. Fig. 6 shows the trend of this heading during the studied timeframe indicating that these deposits had a relatively slow upward trend over time and were associated with specific changes during the remaining period. The general trend of changes in the debtors of letters of credits letters and guarantees is estimated using regression (Table 6).

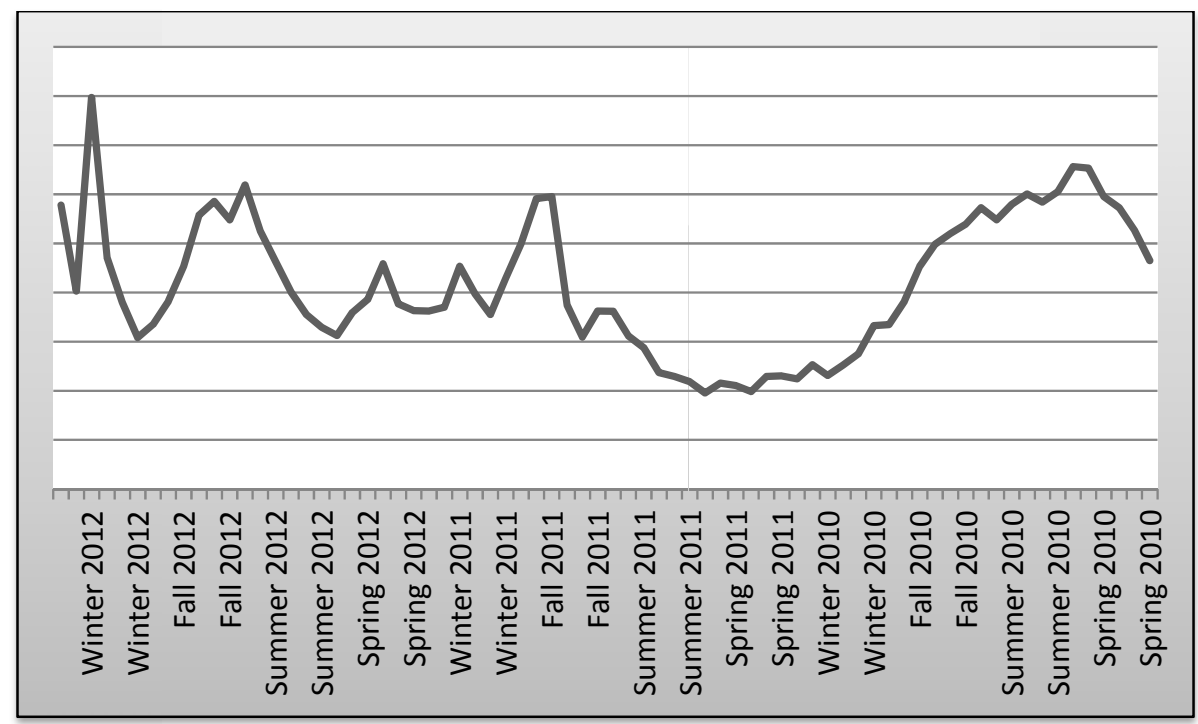

Fig. 6. Trend for debtors of credits letters and guarantees

Table 6

Estimated trend line for prolonged deposits

\begin{tabular}{ccc}
\hline Row & Parameter & quantity \\
\hline 1 & The width of the source & 6675039 \\
2 & The slope of the line & -509.25 \\
3 & The coefficient of determination & -0.011 \\
\hline
\end{tabular}

Using the estimated parameters, the regression equation is as follows: $\mathrm{Y}=\mathrm{f}(\mathrm{t})=6657039-509 \mathrm{t}$, which has a negative slope for each timeframe showing an descending trend. The estimated equation indicates over $1.1 \%$ of the changes.

\subsubsection{Analysis of the liquidity trend:}

This heading includes the accounts of the fund, deposits in the central bank, inventory turnover of current accounts in other banks, foreign currency deposits, bonds and foreign exchange. Fig. 7 shows the trend of this heading indicating that it had a relatively upward trend over time. The figures showed slow growth during the early period until spring 2011 and were associated with specific changes during the remaining period. After spring 2011, multiple bonds issued, increased deposit rate 
and certificates of deposit led to a growth in the bank's liquidity. The general trend of changes in the liquidity was estimated using regression (Table 7).

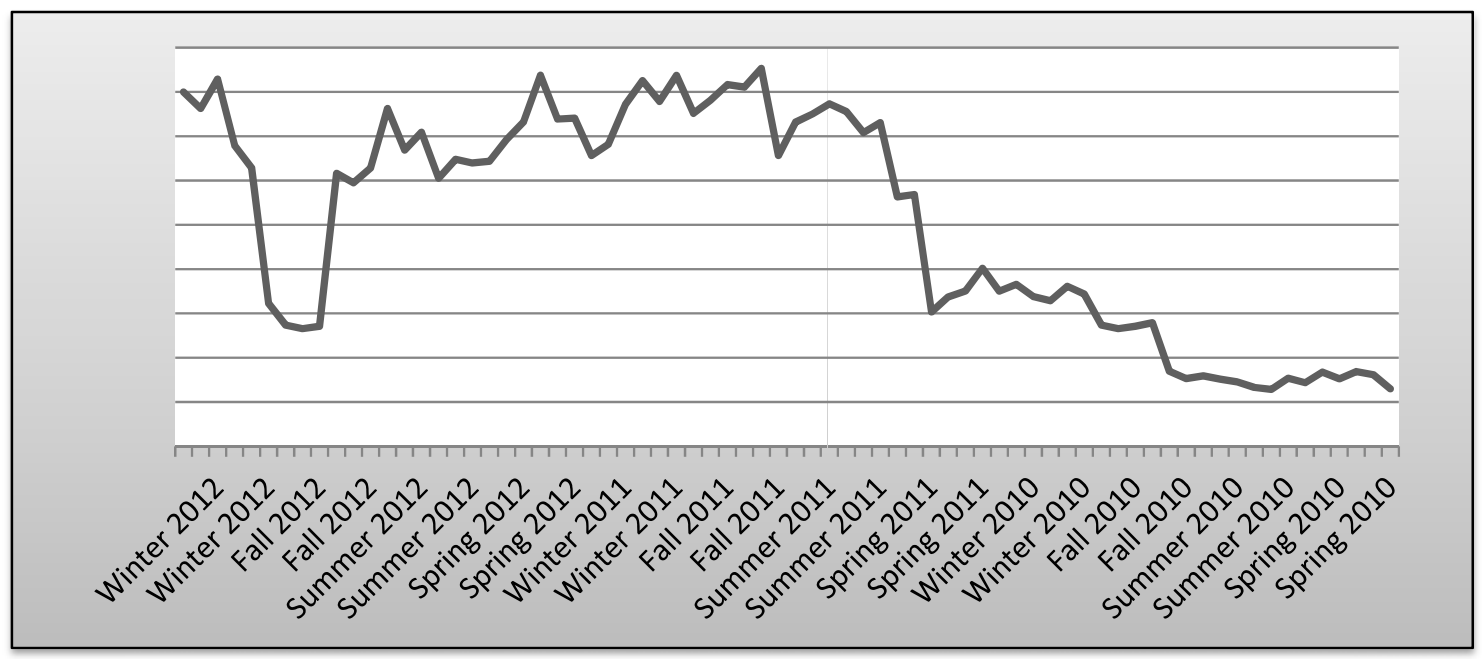

Fig. 7. Liquidity trend

Table 7

Estimated trend line for liquidity trend

\begin{tabular}{ccc}
\hline Row & Parameter & quantity \\
\hline 1 & The width of the source & -40000000 \\
2 & The slope of the line & 41541.347 \\
3 & The coefficient of determination & 0.463 \\
\hline
\end{tabular}

Using the estimated parameters, the regression equation is as follows: $\mathrm{Y}=\mathrm{f}(\mathrm{t})=-40000000+41541 \mathrm{t}$, which has a positive slope for each timeframe showing an ascending trend. The estimated equation indicates over $46.3 \%$ of the changes.

\subsubsection{Comparing the sources and uses of cash}

Fig. 8 compares the items of resources, expenses, and liquidity showing that the growing trend of resources and expenses almost coincide and follow a particular trend, and that the general growing trend of resources is higher with a greater slope than those of the liquidity and expenses. The liquidity growth was almost identical throughout the entire study timeframe and no unusual trend observed.

\subsection{Analysis of the relationship between items}

Assessment of the relationship between changes in the items of resources, expenses and liquidity of the bank relative to each other was conducted using correlation analysis summarized in Table 8 .

\section{Table 8}

The Summary of Correlation Analysis

\begin{tabular}{cccc}
\hline Variable & Liquidity & Resources & Consumptions \\
\hline Liquidity & 1 & 0.815 & 0.687 \\
Resources & 0.815 & 1 & 0.794 \\
Consumptions & 0.687 & 0.794 & 1 \\
\hline
\end{tabular}

This table demonstrates that:

1) There is a direct relationship between the resources and liquidity as the correlation coefficient is positive. 
2) There is a direct relationship between the resources and expenses as the correlation coefficient is positive.

3) There is a direct relationship between the expenses and liquidity as the correlation coefficient is positive.

4) The highest correlation is between the resources and liquidity as the coefficient $(0.815)$, which is close to 1 .

5) The liquidity and expenses display the lowest correlation with a coefficient of 0.678 .

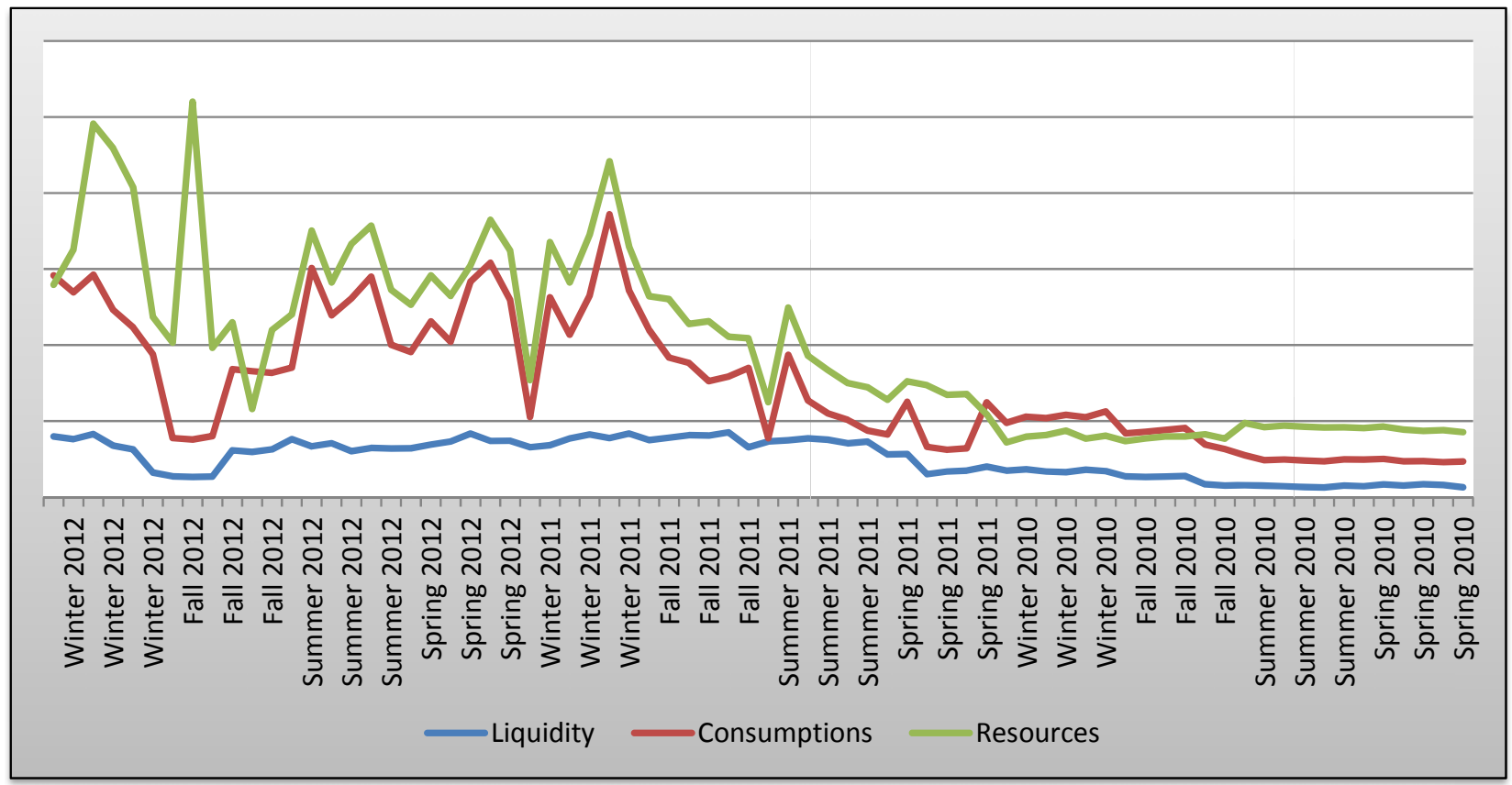

Fig. 8. The Trend of Consumptions, Resources \& Liquidity

\section{Conclusion}

In this investigation, the data were collected by census method and random sampling was not employed. In addition, due to the descriptive method for the trend analysis based on timeframes, the hypothesis testing was avoided. This study was to answer the following questions through trend analysis:

In this study, the components of resources were classified into the three general categories were classified deposits, loans received from banks, and other resources. The other resources have more ascending growth than other categories. Items placed in the facilities received from other banks show weaker and slower growing trends than other categories. The components of expenses were classified into three general categories including total facilities, past due and deferred receivables, and other expenditures. The total facilities have more ascending growth than other categories. Items placed in past due and deferred receivables show weaker and slower growing trends than other categories. The growing trend of liquidity in the studied timeframe show a slow growth slope nearly identical over the entire timeframe and not unusual trend is observed. The growing trend of resources and expenses almost coincide and follow a particular trend, and that the general growing trend of resources is higher with a greater slope than those of the liquidity and expenses. The liquidity growth was almost identical throughout the entire study timeframe and no unusual trend observed. There was a direct 
relationship between the resources and liquidity as the correlation coefficient was positive. Similarly, there was a direct relationship between the resources and expenses as the correlation coefficient was positive. In addition, there was a direct relationship between the expenses and liquidity as the correlation coefficient was positive. In our survey, the highest correlation was between the resources and liquidity as the coefficient (0.815) was closer to 1 and the liquidity and expenses represented the lowest correlation with a coefficient of 0.678 .

\section{Acknowledgement}

The authors would like to thank the anonymous referees for constructive comments on earlier version of this paper.

\section{References}

Balasubramanyan, L., \& VanHoose, D. D. (2013). Bank balance sheet dynamics under a regulatory liquidity-coverage-ratio constraint. Journal of Macroeconomics, 37, 53-67.

Calvo, G. (2012). Financial crises and liquidity shocks a bank-run perspective.European Economic Review, 56(3), 317-326.

Distinguin, I., Roulet, C., \& Tarazi, A. (2013). Bank regulatory capital and liquidity: Evidence from US and European publicly traded banks. Journal of Banking \& Finance, 37(9), 3295-3317.

Fecht, F., Nyborg, K. G., \& Rocholl, J. (2011). The price of liquidity: The effects of market conditions and bank characteristics. Journal of Financial Economics,102(2), 344-362.

Imai, M., \& Takarabe, S. (2011). Transmission of liquidity shock to bank credit: Evidence from the deposit insurance reform in Japan. Journal of the Japanese and International Economies, 25(2), 143-156.

Hauck, A., \& Vollmer, U. (2013). Emergency liquidity provision to public banks: Rules versus discretion. European Journal of Political Economy, 32, 193-204.

Lovin, H. (2013). Determinants of the liquidity in Romanian interbank deposits market. Procedia Economics and Finance, 5, 512-518. 